\title{
Electrochemical Impedance Spectroscopy Investigation of a Polyimide Coating on Q345 Steel
}

\author{
Yubao Qian ${ }^{1,2}$, Hongwu Zhu ${ }^{1}$ and Ding Feng ${ }^{2, *}$ \\ ${ }^{1}$ China University of Petroleum, Beijing, 102249, P.R. China \\ ${ }^{2}$ Yangtze University, Jingzhou, 434023, P.R. China \\ *E-mail: fengd0861@163.com
}

doi: $10.20964 / 2017.04 .42$

Received: 26 December 2016 / Accepted: 14 February 2017 / Published: 12 March 2017

\begin{abstract}
In the present work, polyimide coated turbodrill Q345 steel was prepared with different coating thicknesses $(30,50$ and $80 \mu \mathrm{m})$. The corrosion resistance properties of those samples (exposed to a $3.0 \% \mathrm{NaCl}$ solution) were performed by electrochemical impedance spectroscopy (EIS). Obtained impedance parameters were utilized to evaluate the effectiveness of anticorrosive properties. Pull-off adhesion and microhardness of samples which was exposed before and after to the corrosive environment were carried out to reveal the relationships between the degradation process and the mechanical properties changes in coating/metal system. Polyimide coated samples exhibit high adhesion and enhanced anticorrosion characteristics.
\end{abstract}

Keywords: Electrochemical impedance spectroscopy; Corrosion; Polyimide; Pull-off adhesion; Microhardness

\section{FULL TEXT}

(C) 2017 The Authors. Published by ESG (www.electrochemsci.org). This article is an open access article distributed under the terms and conditions of the Creative Commons Attribution license (http://creativecommons.org/licenses/by/4.0/). 